\title{
State regulation of supply chains through the introduction of goods marking
}

\author{
Irina Sharova, Elena Slepenkova, Dmitry Sobolev, Michail Melnikov, and Olga Rykalina \\ Plekhanov Russian University of Economics, Moscow, Russia
}

\begin{abstract}
Among the most acute problems of the modern economy is not only reducing the cost and improving the efficiency of supply chains, but also their protection from the influence of the shadow economy. In this case, the greatest threat is the illicit trafficking of industrial products. Authors analyze state regulation of supply chains in Russia and abroad, consider the prospects for the development of digital marking and traceability of goods as a method of state regulation of supply chains. The article emphasizes that the existing marking system contains a number of shortcomings. The authors propose mechanisms to improve state regulation of supply chains in modern conditions.
\end{abstract}

\section{Introduction}

Nowadays, supply chains and their regulation are of paramount importance both for a single company and for the country as a whole. The supply chain efficiency is based on the level of transport infrastructure development, as well as the quality and speed of the various services: customs, veterinary control, tax control, and so on. On the part of the state, one of the priority tasks is to create product supply chains that will ensure the movement of manufactured products from producers to end consumers with the most effective protection against counterfeit and substandard goods. This is especially important given the ever-increasing share of illegal products in circulation. Thus, according to official data, up to $35 \%$ of the total turnover of goods in Russia can be attributed to illicit trafficking.

From the above, it follows that the relevance of studying supply chains and their regulation at the state level is extremely high. One of the most effective and most promising ways for state regulation of supply chains is the introduction of an electronic marking system to ensure transparency. However, this area is completely new and unexplored in Russia, so to increase the effectiveness of this measure the study of the experience of other countries in similar projects is required.

\section{Materials and methods}

Theoretical and methodological basis of the study are scientific and practical and specialized literature covering this issue, periodic and specialized print publications and reports of various experts on the selected topic.

The article analyzes state regulation of supply chains in Russia and abroad, examines the prospects for the development of goods digital marking and traceability as a method of state 
regulation of supply chains, proposes mechanisms to improve state regulation of supply chains in modern conditions.

The analysis is based on information from open sources: the study of publications in scientific and business journals and mass media, as well as data from sites available in Russia.

\section{Results and discussion}

One of the most acute problems facing the Russian economy is the increase in the scale of shadow economy. At the moment, the volume of the shadow economy is $39 \%$ of the country's GDP, which has a very negative impact on the country's economy. One of the shadow economy components is the illegal turnover of industrial products, the damage of which is estimated by experts at 43 billion dollars. A significant share, about $40 \%$ of the illicit trade in products is industrial products. It should be noted that these are only approximate estimates, since it is impossible to assess the real extent of the problem, since there is no reliable information, and the existing mechanisms and tools allow to do so only indirectly.[1]

Illegal turnover of industrial products - processes (stages) of production, processing, sale (purchase and sale or delivery) of industrial products, including import and export of industrial products, including counterfeit industrial products and falsified industrial products, as well as related processes of prepacking, packaging, marking, storage and transportation, carried out by legal entities and individual entrepreneurs in violation of the requirements of the legislation of the Russian Federation and international treaties of the Russian Federation, as well as established by effective court decisions or authorized state authorities. [2]

It can be concluded from this that illicit trafficking in industrial products can be carried out at any stage of the supply chain [3,4]. This in turn leads to the need for government regulation and supply chain management. One of the ways the government manages the supply chain is to combat illicit trafficking of industrial products.

\subsection{Digital marking and tracking system for goods in Russia}

In order to combat illicit trafficking, in 2015, the President of the Russian Federation decided to create the State Commission to Combat Illicit Trafficking of Industrial Products (hereinafter - the State Commission) and appointed the Minister of Industry and Trade and commissions to combat illicit trafficking of industrial products in the Russian Federation constituent entities as its head. [5]

Among the main tasks of the State Commission are:

- Coordination of the activities of government bodies at all levels, as well as of various organizations and commissions in order to carry out activities to combat illicit trafficking in industrial products on the territory of the Russian Federation;

- Development of measures to combat and prevent illicit trafficking in industrial products, as well as to increase the effectiveness of these measures;

- Interaction with foreign colleagues aimed at combating illicit trafficking in industrial products, including in the development of draft international documents;

- Conducting research and analysis of the current situation in the field of illicit trafficking in industrial products in the Russian Federation;

- Development of proposals for the creation of state policy in combating illicit trafficking of industrial products, including through the preparation of regulatory legal acts in combating illicit trafficking of industrial products;

- Preparation and submission on a regular basis of reports on the state of illicit trafficking of industrial products in the Russian Federation; 
- Solving other tasks related to the fight against illicit trafficking of industrial products in accordance with the legislation of the Russian Federation. [5]

In addition, in order to implement the Decree of the President of the Russian Federation on Additional Measures to Combat Illicit Trafficking in Industrial Products in 2016, the State Commission developed a Strategy to Combat Illicit Trafficking in Industrial Products in the Russian Federation for the period up to 2020 and the planning period up to 2025, a document that considers the main provisions, characterizes the current state of the sphere, identifies problems and determines the main priorities, analyzes international experience and formulates goals, objectives, principles and a list of basic measures in the field of combating illicit trafficking in industrial products. This Strategy notes that illicit trafficking of industrial products is one of the most serious problems that have a negative impact not only on the situation in individual industries, enterprises and the economy as a whole, but also on the society interests. The high volume of turnover of industrial products hampers the economy development (budget losses, reducing the economy attractiveness), harms manufacturers and consumers, as well as can also threaten the consumers' life and health.

The Strategy identifies a number of industries in which there is illicit trafficking of industrial products in the largest volume: food, light, pharmaceutical and medical, automotive, aviation, agriculture, fuel, chemicals, electronics, construction, children's goods industry and mechanical engineering. Thus, illicit trafficking of industrial products is observed in a large number of key industries.

Among the reasons for the problems are the low level of legislation, the lack of control by state bodies, the difficult geopolitical and economic situation, the peculiarities of the internal economic situation in the country (low income, mentality). Another important feature of Russia is the fact that the control over the turnover is carried out by a large number of state bodies at different levels, guided by various laws and regulations and other documents.

Among the main, aimed at combating illicit trafficking of industrial products in Russia in this Strategy are:

- Improving the legislation of the Russian Federation;

- Formation of an intolerant attitude to the consumption of industrial products that are in illegal circulation;

- Development and implementation of a comprehensive state system for monitoring the situation in combating illicit trafficking of industrial products in the Russian Federation;

- Implementation of traceability systems for industrial products at all stages of their production, movement and sale;

- Development of international cooperation in combating illicit trafficking of industrial products.

- Establishment of proportionate sanctions for violations in turnover of industrial products.

One of the ways to counteract illicit trafficking of industrial products on the territory of the Russian Federation was proposed a system of marking goods with control (identification) signs, which are designed to carry out checks on the legality of industrial products by public means, in particular through cell phones.

One of the first marking systems, which began to operate in the Russian Federation in 2005, is Unified State Automated Information System (hereinafter - USAIS). USAIS is designed to exercise state control over the volume of manufacture and turnover of ethyl alcohol, alcoholic and alcohol-containing products.

The alcoholic beverage market is currently developing extremely dynamically. Unfortunately, the Russian Federation is one of the leaders in alcohol consumption and the number of deaths caused by it. An important cause of the high mortality rate is the high proportion of counterfeit alcoholic beverages. It is to solve this problem that USAIS was developed. This information system allows to solve a large number of issues, including: 
- $\quad$ Record-keeping of production and turnover of ethyl alcohol, alcoholic and alcoholcontaining products, as well as monitor the excise tax accrual;

- Analyzing the current state of production and turnover of ethyl alcohol, alcoholic and alcohol-containing products;

- To make it more difficult to sell counterfeit products by checking the accompanying documents certifying the legality of production and turnover of ethyl alcohol, alcoholic and alcohol-containing products.

At the moment, USAIS continues to operate on the territory of the Russian Federation. The developers continue to improve the system, trying to make it as efficient as possible. Nevertheless, the market for illegal products continues to exist.

The next stage in the marking system development was the creation of the Center for Development of Advanced Technologies on the basis of public-private partnership. The main task of this Center was the development, implementation and monitoring of the Unified National System of Digital Marking and Traceability of Goods "Fair Mark", aimed at improving the domestic market transparency. With this system, the consumer has the opportunity to get all the necessary information on the product of interest, representatives of the legal business to increase market share and protect their brand and reputation, as well as automate and optimize supply chain management processes, the state gets quick access to information on commodity markets.

As part of the implementation of the "Fair Mark" system, the IS "Marking" was developed to combat illicit trafficking of products. It was created to regulate the turnover of products on the market of the Eurasian Economic Union (hereinafter - EAEU). IS allows to reduce the damage from illicit trafficking of industrial products and increase the level of control over the product turnover. Controlled goods are marked with a special identification mark with a special radio-frequency tag (RFID-tag), from which all the necessary information can be read. It is worth noting that the control signs are ordered at the enterprise "Goznak" and are delivered to the enterprise for free. It is planned that this IS will be used to ensure the traceability of a large number of different goods, which will significantly increase the volume of tax and customs revenues, as well as reduce budget costs for the commodity market control. [6]

The pilot project on the marking of goods with RFID tags has been carried out since August 1, 2016, when the Chairman of the Government of the Russian Federation D. A. Medvedev signed the corresponding decree No. 787 "On the implementation of a pilot project to introduce the marking of goods with control (identification) marks for the heading "Clothing items, clothing accessories and other products made of genuine fur". This decree obliges manufacturers, importers from the EAEU countries, sellers and other participants in the fur market to transmit information on fur products marking. All interaction is carried out through a special Marking Information Resource, in which all participants in the turnover of fur products must be registered, and through which they order control signs for goods marking. [7] Administrative and criminal liability is provided for market participants who use unmarked natural fur products.

It is worth to remark that this pilot project can be considered a success. According to official data of the Federal Customs Service (FCS) of Russia, about 240 thousand units of fur products were imported to Russia before the marking began, and about 70 thousand more were produced on the territory of our country. However, in the first year of the pilot project, more than 5 million RFID tags were created. Consequently, previously there were more than 4.7 million fur coats "in the background", which are now "whitewashed". According to some sources, this brought the country's budget about 190 million dollars. [8]

The second stage of implementation of marking was the experiment of implementing the Drug Movement Monitoring System (hereinafter - DMMS). Note that by December 2018, 
more than 11,000 companies had participated in it, registering 1.7 thousand drugs, and more than 17 million packages of drugs had been marked. [9]

At the moment, a voluntary experiment on marking of tobacco products is already underway, with the participation of major tobacco manufacturers and distributors. Almost 250 enterprises took part in this experiment and received 155 million control and identification marks for marking their products. Marking of tobacco products became mandatory for manufacturers on March 1, 2019. [10]

Active development of marking systems and experiments to implement these systems in other industries are taking place [11]: mining and processing of precious stones and metals, production of perfumes and eau de toilette, tires and covers, bicycles, various items of clothing, bed and kitchen linen, shoes and photographic equipment.

It is also worth highlighting another project, namely the food products marking. It is carried out in the veterinary information system, which is called the Federal State Information System (FSIS) "Mercury". Since July 1, 2018, food products marking is mandatory. The main goal of creating FSIS "Mercury" is to create a unified information environment for food products, traceability system, which will increase biological and food safety. According to the project initiators' idea, all food products must be marked at all stages of circulation, which requires veterinary examination. [12]

\subsection{Foreign experience in supply chain regulation}

For the effective implementation of the marking system, it is extremely important to study foreign experience, as some countries have long used this mechanism to combat illicit trafficking of industrial products.

For example, EU countries have been thinking about marking issues since 2000. At the moment, livestock, food, pharmaceutical, alcoholic and tobacco products are subject to mandatory marking there. The choice of these industries is due to the high risks to human health. Also, the subject to marking are various logistical and transport facilities: ships carrying vehicles and passengers, shipping containers, maritime services.

The traceability system also works in Brazil. There, unique identification numbers are assigned to medications, as well as any container in which they are stored and transported. In addition, Brazil has traceability programs for fruit and tobacco products.

In the USA, great importance is given to drug marking, but a big drawback is the fact that there is no uniform standard of rules for the information exchange. This significantly complicates the information exchange at different stages of manufacture.

In most countries, various non-food products are marked: art objects, automotive industry, fashion, cosmetics, electronics. These products are actively marked by the countries that are leaders in their manufacture: the United States, Japan, the EU member states, the United Kingdom [13], and the CIS [14].

For Germany, as well as for Sweden, the marking of various technical components is of great importance: air suspension systems, parts and components of railway transport.

Projects on the use of marking of pharmaceutical products and canned food are being implemented in the People's Republic of China.

In Armenia, much attention is paid to the food products traceability. More than 40 product groups are marked there: dairy products, canned food, fish, beer, juices, beverages, tea, coffee.

For Kazakhstan and Kyrgyzstan, it is extremely important to mark agricultural products, as well as fur products.

Thus, it can be concluded that many countries have been using the marking of industrial products for quite a long time $[15,16,17]$. This means that this method of combating counterfeit products is effective. Consequently, it is extremely important for Russia to 
continue to study foreign experience and cooperate with foreign colleagues to develop an effective marking system.

\subsection{Prospects for the development of digital marking and tracing of goods as a method of state regulation of supply chains}

To analyze the prospects for the development of digital marking in Russia, FSIS "Mercury" was chosen as one of the most actively developing and relevant today. At this point it is difficult to give an unique assessment of the IS effectiveness. However, it can already be said that the companies participating in the food marking project have encountered a number of difficulties and problems in the system implementation and operation.

After receiving and analyzing the first results of the FSIS "Mercury" operation, the coordinator of the marking system - the Ministry of Industry and Trade of the Russian Federation - decided on the need to make changes in the process of implementing the introduction of mandatory marking of food products. For this purpose, requests were sent to the business community and federal government agency (hereinafter - FGA), with a request to give a generalized assessment of the project being implemented, to identify its main shortcomings and ways to solve these problems.

After analyzing the answers received from representatives of the business community and FGAs, the following conclusions can be drawn. The business community has made preparations to purchase the necessary equipment and software, train employees on the new requirements, and establish new business processes with participants in the production chain. At the same time, most representatives of the business community have a negative attitude to the introduction of FSIS "Mercury" into use. Among the main reasons are a large number of problems and risks of using this system. Thus, many companies note the low degree of readiness of the Information System itself, which leads to a large number of failures in its operation. At the core of these failures is the lack of uniform classification of products by suppliers and manufacturers, which leads to frequent errors in IS operation. Another significant problem is the lack of uninterrupted access to the Internet throughout the country, which is necessary for the marking process implementation. But even where this access is available, system participants face problems associated with the inability to quickly process large amounts of data coming from supply chain participants at one time. In addition, while the production of fur coats, alcohol, tobacco, and other industrial products is handled by a limited number of large manufacturers, in the food industry there are a large number of small enterprises. For them, the introduction of FSIS "Mercury" will entail a large amount of costs caused by the need to purchase new equipment and software, increase the number of employees, complicate all stages of products manufacture and transportation. Another problem is the time required for the operation of FSIS "Mercury", because its use complicates and lengthens the turnover process of food products, but it is not always acceptable because of the limited shelf life of food products. In addition, some business representatives point out gaps in the legislative plan, which also has negative consequences.

FGAs also carried out a large amount of preparatory work aimed at speeding up and simplifying the marking system implementation. Thus, in many regions, "roadmaps" were developed for the IS implementation in the work, special retraining and advanced training programs were created for employees who should work with FSIS "Mercury". Some regions at the expense of budgetary funds procured the necessary equipment and software for employees of state veterinary services. In contrast to the business community's representatives, regional authorities' representatives have a positive attitude to the introduction into use of FSIS "Mercury", saying that this system is highly necessary. Among the shortcomings, they also note the low readiness degree of the Information System itself, which leads to a large number of failures in its operation, the low availability degree of the 
Internet in remote areas of the regions, as well as gaps in the legislative plan, which has negative consequences.

Thus, it can be concluded that the use of various information systems aimed at forming a system of goods traceability, and FSIS "Mercury", in particular, has a large number of disadvantages [18]. Most of them are caused by the lack of a comprehensive analysis of the situation, which allows to look at the issue not only from the perspective of the supervisory authority, but also from the perspective of the direct participants in the marking system.

To resolve this problem, consulting with various stakeholders in advance, which will allow for a better elaboration of mechanisms for implementing a mandatory labeling system is recommended. It is also worth noting the need to be sure to conduct voluntary experiments to implement marking in the future. This will allow to debug the system, identify "rough spots" and eliminate them. In cases where the system is launched without prior testing, it is quite difficult to make any adjustments. It is also worth considering the possibility of gradually introducing a mandatory marking system for the entire product range, which will reduce the system cost, but increase its efficiency.

\section{Conclusions}

Among the most acute problems of the modern economy is not only reducing the cost and improving the efficiency of supply chains, but also their protection from the influence of shadow economy. In this case, the greatest threat is the illicit trafficking of industrial products. In this regard, the Government of the Russian Federation is actively working to combat counterfeit products. One of the most effective methods of this struggle is the development, implementation and use in various sectors of mandatory marking system. This system allows to track the product at any stage of the production chain, to find out who is the supplier of raw materials, and who is the final product manufacturer. This makes the market more transparent and protects producers and consumers from low-quality products.

To date, the Center for the Development of Advanced Technologies is engaged in the development of a mandatory marking system. Its employees oversee the IS implementation, which allows the tracking of marked products in various industries. In recent years, the list of goods subject to mandatory marking has expanded tobacco products, medicines, and food products. The development and implementation of new programs for the introduction of a marking system for other industrial products is constantly ongoing.

The system as a whole, of course, is not perfect and contains a number of flaws. However, their elimination and the use of modern technologies will effectively combat the shadow economy.

\section{References}

1. V. V. Radaev, E. S. Berdysheva, N. V. Conroy, Z. V. Kotelnikov, Econ-Sociol. Research, 418 (2017)

2. Strategy for combating illicit trafficking in industrial products in the Russian Federation for the period up to 2020 and the planning period up to 2025 (2020) http://static.government.ru

3. O. Saginova, E. Tsenina, Y. Saginov, D. Zavyalov, Web of Conferences, 210, 15014 (2020)

4. J. Barata, P. R. da Cunha, Int J Adv Manuf Technol, 112, 2109 (2021)

5. Decree of the President of the Russian Federation on Additional Measures to Counteract the Illegal Turnover of Industrial Products, http://pravo.gov.ru 
6. The official website of Tsentrinform JSC, https://center-inform.ru

7. Government Resolution, 235 "On conducting an experiment on the marking of goods with control (identification) marks for the heading "Clothing items, clothing accessories and other products made of genuine fur", http://marking2016.ru

8. "Grey" fur: what the fight against counterfeit fur coats has led to, https://www.rbc.ru

9. Center for the Development of Advanced Technologies (CDAT). Press release on drug marking (2018) https://crpt.ru

10. CDAT. Press release on tobacco products (2018) https://crpt.ru

11. A. I. Boginsky, L. S. Zelentsova, A. I. Tikhonov, Springer, 115, 436 (2020)

12. FSIS “Mercury”, http://меркурий-россельхознадзор.pф

13. F. Asche, G. Sogn-Grundvåg, D. Zhang, A. L. Cojocaru, J. A. Young, Journal of International Food \& Agribusiness Marketing, 33(1), 53-68 (2021)

14. D. A. Willette, S. C. Esteves, B. Fitzpatrick, M. L. Smitha, K. Wilson, X. Yuan, Marine Policy, 125, 104380 (2021)

15. S. Shahrabani, Isr J Health Policy Res, 10, 25 (2021)

16. A. N. Livingston, T. J. Mattingly, Journal of the American Pharmacists Association, 61(1), e119 (2021)

17. G. Harpaz, Journal of World Trade, 55(2), 359 (2021)

18. B. L. Nguyen, E. L. Lydia, M. Elhoseny, I. V. Pustokhina, D. A. Pustokhin et al., IoT data,"Computers, Materials \& Continua, 65(1), 87 (2020) 